\title{
Literatura como contrapoder: la construcción identitaria femenina en la obra de escritoras franco-magrebíes
}

\section{Literature as a counterpower: The construction of female identity in the work of Franco-Maghrebi women writers}

\author{
SOlEDAD DíAZ AlarcóN \\ Universidad de Córdoba \\ 1r2dials@uco.es
}

\begin{abstract}
This work explores the female imagery of Franco-Maghrebi women writers who published their works in the 1980s and 1990s and those who came after. It analyses the identity construction of a group marked by ethnic duality through their expression and their narratives in which they stake their claims: autobiographical writing, particular uses of the French language (slang and orality), the private and public spaces and the stances of their protagonists (acceptance, pretense, flight or uprooting). The study ends with an assessment of the editorial recognition and reception of this literature by critics.
\end{abstract}

\section{Key-words}

Franco-Maghrebi women's literature, Beur literature, writing and counter-power, construction of identity.

\begin{abstract}
Résumé
Cette étude explore l'imaginaire féminin des écrivaines Franco-Maghrébines qui ont publié leurs œuvres dans les années 1980-1990 et de leurs continuatrices. Elle analyse la construction identitaire d'un collectif marqué par la dualité ethnique à travers son expression et ses récits, où les écrivaines véhiculent leurs dénonciations: autobiographie, usage particulier de la langue française (argot et oralité), espaces privés et publics et les positions de leurs protagonistes (acceptation, faux-semblant, fuite ou déracinement). L'étude comprend une évaluation de la reconnaissance éditoriale et de la réception de cette littérature par la critique.

Mots-clés

littérature féminine Franco-Maghrébine, littérature Beur, écriture et contrepouvoir, construction de l'identité.
\end{abstract}




\section{Introducción}

“Écrire, c’est résister”, esta afirmación de Nina Bouraoui (2019) manifiesta el sentir de varias generaciones de escritoras franco-magrebíes erigidas, sin pretenderlo, en portavoces del clamor de un grupo poblacional que, por las características que lo definen, (dualidad étnica y género), buscan su espacio, su identidad y su reconocimiento como ciudadanas de pleno derecho en una sociedad occidental, sin renuncias ni sacrificios impuestos. Escritoras como Farida Belghoul, Antoinette Ben Kerroum-Covlel, Sakinna Boukhedenna, Djura, Leïla Sebbar, Tassadit Imache, Ferrudja Kessas, etc., nacidas de padres inmigrantes magrebíes, inician su andadura literaria en los años 80 (algunas varias décadas antes como Djamila Debêche $^{1}$ o Assia Djebar ${ }^{2}$ ) con publicaciones de corte autobiográfico, especialmente sobre la inmigración y sus consecuencias en una segunda generación de mujeres nacidas o llegadas a Francia a una edad temprana, una generación dividida entre dos culturas, desprovista de referencias identitarias y condenada a la marginalidad.

Los estudios literarios que abordan esta temática centran sus análisis en la noción de subversión, en la estela de los estudios de género y estudios postcoloniales, tales como Déjeux, 1994; Segarra, 1997; Chaulet-Achour, 1999; Donadey 2001; Hughes, 2001; Gontard, 2005; Gafaiti et Crouzieres-Igenthron, 2005; Boehmer, 2005; Naudier et Ravet, 2005; Petit, 2008; Détrez, 2010, etc. En ellos, se pone de manifiesto la opresión y el sometimiento del colectivo femenino franco-magrebí y cómo autoras que pertenecen al mismo emprenden su particular revuelta reivindicando la actividad de la escritura como principio de resistencia, como acción "transgressive" (Détrez, 2010: 2). Esta transgresión se traduce en el rechazo a ser identificadas con la imagen estereotipada de inmigrante de banlieue de gran ciudad, objeto de desprecio y exclusión, y la reclamación del reconocimiento a la singularidad, a la dignidad y al respeto a la diferencia. Se trata pues de la lucha de una generación por el derecho a expresarse, de su necesidad vital "d'écrire, de respirer, d'exister" (Gadant, 1984: 1992), o de transgredir los códigos, siguiendo la propuesta de la escritora franco-argelina Hélène Cixous:

L'écriture permet de dépasser les codes. Dès que tu te laisses conduire au-delà des codes, ton corps plein de crainte et de joie, les mots s'écartent, tu n'es plus enserrée dans les plans des constructions sociales, tu ne marches plus entre les murs, les sens s'écroulent, le monde des rails explose, les airs passent, les désirs font sauter les images, les passions ne sont plus. (Cixous, 1986: 61)

1 La autora Djamila Debêche tiene doble nacionalidad, argelina y francesa. Se formó en la escuela colonial y, en la actualidad, en sus artículos y conferencias, aboga por la emancipación de la mujer musulmana en Francia. En sus obras, Leïla, jeune fille d'Algérie (1946) y Aziza (1955), de considerable tinte autobiográfico, sus heroínas se enfrentan a dificultades de reconocimiento y aceptación por parte de su sociedad, en la que luchan por afirmar su autonomía. Junto a Taos Amrouche, será una de las fundadoras de la literatura femenina argelina.

2 Assia Djebar, con doble nacionalidad, argelina y francesa, al igual que Debêche, escribe su primera novela, $L a$ Soif, en 1957 y su producción continuará hasta 2003 erigiéndola como figura ineludible de la escritura femenina en Argelia y el Magreb. 
La escritura se vuelve, por tanto, lugar de resistencia (Bueno Alonso, 2004), mecanismo de lucha contra un discurso patriarcal transmitido cultural y tradicionalmente por el hombre, en estos casos en contexto francés, tanto en el espacio social (instituciones, organismos, entorno profesional, cultural, etc.) como en el familiar (padres, hermanos, esposos), con una intención eminentemente coercitiva. Este discurso pretende ser garante de una tradición asimismo subyugante en la que la religión ostenta una posición privilegiada e impone la segregación de géneros. La mujer, para recuperar el equilibrio de roles y hacer que su voz se escuche, opta por el camino de la creación. Un contrapoder individual que constituye un discurso de liberación gracias a la fuerza de la palabra. En este sentido, la escritura no solo es entendida desde una posición comprometida, sino que deviene un recurso sumamente eficaz para alcanzar la emancipación y el respeto deseados.

"L'acte d'écrire est ma première liberté", así de sincera y categórica se muestra la escritora argelina Malika Mokeddem en la entrevista concedida al periódico El Watan (septiembre, 2006). De hecho, la reflexión sobre la escritura ocupa la mayoría de los personajes de ficción de sus obras y constituye la voz de la propia autora, la "femme engagée" (Bueno Alonso, 2004: 13).

La fertilidad social que la maternidad le confiere a la mujer es reemplazada por la fertilidad intelectual que permite explorar el poder creativo que les proporciona la complejidad de la feminidad y el mestizaje cultural, y salir "du mutisme total que la société patriarcale maghrébine leur dicte” (Bouhayat, 2017: 52). Por ello, la palabra creativa contrarresta un discurso que devalúa a la mujer, supera los escollos que obstaculizan la libertad para decidir sobre su vida y su futuro, le permite descubrir el mundo, crear un universo propio y recuperar su poder, que se deriva del poder mágico de la palabra, manteniéndose en contacto con la realidad.

Pero ¿qué autoras componen este colectivo?, ¿qué les preocupa?, ¿cuáles son sus reivindicaciones o denuncias?, ¿cuáles son las estrategias implementadas en sus obras para alcanzar sus objetivos? A pesar de la complejidad de estas cuestiones intentamos con este estudio acercarnos a este grupo de autoras a través de sus escritos. De hecho, nuestro objetivo principal en este trabajo es explorar el imaginario femenino de femme immigrante maghrébine o issue de l'immigration construido por un grupo de autoras englobadas en lo que ha venido a denominarse la literatura beur, así como sus continuadoras. Nuestro foco de interés son los tres ejes sobre los que pivota la construcción de su universo: su condición de franco-magrebí, su condición de mujer, su condición de escritora. Para ello, analizamos la construcción identitaria de este colectivo femenino a través de su narración y de su expresión: escritura autobiográfica en lengua francesa y usos particulares de la lengua (argot y oralidad), los espacios privado y público, personajes a través de los cuales vehiculan sus denuncias y su posicionamiento, y estrategias adoptadas en sus obras frente al abuso (acep- 
tación, fingimiento, huida y desarraigo). Asimismo, analizamos el reconocimiento de esta literatura por crítica y público.

El primer reto al que nos enfrentamos es la dificultad de establecer un corpus preciso que represente la escritura femenina de inmigración, dificultad, por otra parte, inherente a las literaturas calificadas de "émergentes" que, según Bonn (2001: 44)³ son precursoras de los nuevos espacios culturales. El segundo reto es poder determinar el concepto de literatura beur, ya que no todas las autoras se reconocen en él, como es el caso de Leïla Sebbar, quien afirma que "la littérature beur n'existe pas" (citado en Chaulet-Achour, 1990a: 184). En las siguientes líneas intentamos dilucidar dichos desafíos.

La literatura beur ${ }^{4}$ está constituida por jóvenes escritores nacidos de padres inmigrantes que publican en los años 80 una serie de novelas, en su mayoría de carácter autobiográfico, sobre la inmigración y sus consecuencias en la segunda generación. Las autoras, en particular, quieren dar a conocer cómo viven, dejar constancia de su exclusión, de sus conflictos identitarios y de su sometimiento. Sus narraciones, contextualizadas en Francia, tienen como protagonista un espacio y la relación del individuo con su entorno, el de los suburbios, que filtra su hibridez cultural en la lengua común a todos, el francés. Sin embargo, muchas de estas autoras no quieren verse encerradas en la categoría de "literatura beur". Farida Belghoul, Leïla Sebbar o Sakinna Boukhedenna, por ejemplo, niegan el concepto o lo impugnan por su restricción a un conjunto de obras identificadas por la etnia y el objetivo primario de sus productoras, quienes comparten ciertas experiencias vitales (inmigración y exclusión). De este modo, se restringiría igualmente su público al encontrarse en un espacio temático limitado. La crítica literaria, por su parte, cuestiona la calidad y pobreza estéticas ${ }^{5}$ de estas creaciones, considerándolas faltas de madurez e innovación en la construcción del relato. Finalmente, las casas editoriales han mostrado cierto interés por la obra de estas autoras (más por un fenómeno de mediatización que de calidad literaria), sin embargo, no dejan de catalogarlas como literatura menor $^{6}$. Alec G. Hargreaves sintetiza en esta cita la opinión de varios de los detractores de la literatura beur:

3 "Quels que soient par ailleurs les thèmes de société développés par les littératures émergentes, c'est d'abord l'existence reconnue de ces littératures elles-mêmes qui affirme aux yeux de tous l'existence de l'univers culturel-et politique- dont elles sont les représentantes". (Bonn, 2001: 44)

4 Kettane explica en Droit de réponse à la démocratie française (1986: 20) que "la première fois que le mot 'beur' est apparu dans la presse, c'était en janvier 1982 à propos de Radio Beur, radio libre parisienne créée en novembre 1981 [...]". Por otra parte, Hargreaves (1993: 30) constata la mediatización del término que comenzó en 1982 y alcanzó su éxito en 1983, con la Marche pour l'égalité et contre le racisme, bautizada como la Marche des Beurs.

5 Véase L'anthologie de la littérature algérienne de langue française de Christiane Chaulet-Achour, 1990. Una de las obras pioneras en interesarse por este corpus en Francia y por los planteamientos y temáticas clave de estos autores.

6 Véase la obra de Deleuze y Guattari (1975): Kafka. Pour une littérature mineure, en la que dichos autores afirman: "une littérature mineure n'est pas celle d'une langue mineure, mais plutôt celle qu'une minorité fait dans une langue majeure" (p. 29). También la obra de André Videau (1988): "Le roman beur en question". 
La littérature issue de l'immigration en France est une littérature qui gêne. Les documentalistes ne savent pas où la classer, les enseignants hésitent à l'incorporer dans leurs cours, et les critiques sont généralement sceptiques quant à ses mérites esthétiques. (Hargreaves, 1995: 24)

A pesar de las objeciones, somos de la opinión de que, de un modo u otro, esta literatura expresa un imaginario diferente del representado por la novela francesa canónica, una sensibilidad especial hacia la multiculturalidad y las entidades plurales y abre una nueva vía a la literatura francesa orientándola hacia las interculturalidades y las diferencias. Estas autoras en especial aportan una vis novedosa a lo que se ha escrito hasta ahora sobre inmigración y sociedad francesa. Su mérito ha sido entender la escritura como mecanismo de comunicación y expresión que las autoriza a ejercer la palabra con total libertad y exponer su visión, ya sea herida, traumática o comprometida, de su realidad.

Lejos de ahondar en la complejidad de determinar la inclusión de todas las autoras que forman parte de la controvertida catalogación de la literatura beur, dado que no es el objetivo de este trabajo, nos hacemos eco del exhaustivo listado cronológico que Alec Hargreaves (1992) y Jean Déjeux (1992) establecen de los escritores beurs, según la fecha de sus primeras publicaciones, en el que encontramos la siguiente relación de autoras: Farida Belghoul, Antoinette Ben Kerroum-Covlel, Sakinna Boukhedenna, Djura, Leïla Houari, Tassadit Imache, Soraya Nini, Malika Modeddem, Sapho, Djanet Lachmet, Fatihe Berezak, Fatima Gallaire y Leïla Sebbar. Asimismo, y como indicábamos ut supra, en este estudio analizamos la evolución de esta literatura a través de la mirada y el sentir de escritoras contemporáneas que recogen el testigo de sus predecesoras, publicando sus primeros escritos en los años 2000 tales como Kaoutar Harchi, Nora Hamdi, Houda Rouane, Soraya Nini, Minna Sif, Nadia Berquet, Fatima Nouri, Mélina Gazsi (Farida Laaloui), Souâd Belhaddad, Fatna Gourari, entre otras.

La emergencia colectiva de estas autoras contemporáneas está en primer lugar vinculada sociológicamente a la evolución del proceso de integración y al enraizamiento progresivo de los hijos de los inmigrantes en la sociedad francesa. Pese a las dificultades encontradas (fenómenos de discriminación o segregación urbana) suelen tener más éxito que la generación anterior, sobre todo gracias a la escuela y a la enseñanza superior. Esto les permite hacerse más visibles no solo en el ámbito cultural, sino también, aunque en menor medida, en política y economía. Como afirma Karim Amellal (2014: 2) este fenómeno de creciente integración ha llevado a muchos jóvenes descendientes de inmigrantes a cuestionar sus orígenes, su identidad, su memoria, a deconstruir y luego a reconstruir sus vivencias gracias a la investigación en la universidad, pero también a través de la escritura. Por tanto, la escritura, ya sea en el campo literario, musical o cinematográfico, se transforma,

Hommes \& migrations, 1112, avril-mai, 7-11; y el trabajo de Alec Hargreaves (1995): "La littérature issue de l'immigration maghrébine en France: une littérature 'mineure'?" in Bonn, Charles: Etudes littéraires maghrébines. Littérature des immigrations: un espace littéraire émergent. 
como en las generaciones anteriores, en un medio de expresión, emancipación y protesta, pero también en un marcador de éxito.

En lo que a temática se refiere, es una constante en los diferentes estudios llevados a cabo hasta la fecha sintetizar en un conjunto de temas las preocupaciones que los autores beurs plantean en sus relatos: pobreza, precariedad, conflictos vecinales, dificultades de adaptación en el colegio, prejuicios raciales, racismo, etc. (Desplanques, 1991: 140); en definitiva, el retrato de los jóvenes que crecen en las periferias geográficas y sociales de las grandes urbes francesas. En cuanto a la producción literaria post-beur, la semejanza entre esta y la de sus predecesoras es indiscutible, sobre todo en lo que se refiere al desequilibrio social y a la profundización en este entorno de los barrios pobres de las grandes aglomeraciones de Francia. Sin embargo, el enfoque de este último ha cambiado claramente. El tema de la dualidad cultural y la búsqueda de la identidad que caracterizó a los relatos más vendidos de los años ochenta ha perdido su valor con el tiempo, ya que se ha vuelto irresoluble.

Sirva esta introducción para constatar que la escritura femenina ha demostrado su notable presencia en la literatura contemporánea, porque las mujeres han escrito sobre su realidad, su interrelación en los ámbitos público y privado, y han reivindicado su alteridad, su libertad y el reconocimiento a las diferencias, con el objetivo de mejorar el lugar de la mujer en la sociedad. Beatrice Didier explica:

Plutôt que de créer une littérature à part, les femmes me semblent un renouvellement radical à l'écriture contemporaine. Parce que des femmes écrivent, les hommes ne peuvent plus écrire comme ils le faisaient quand elles étaient réduites au silence. [...] Depuis que les femmes écrivent sans entrave, quelque chose a changé; la conception de l'écrit et la littérature n'est plus la même. (Didier, 1981: 39)

Del mismo modo, y a pesar de las profusas críticas hacia la literatura beur, y su consideración de tendencia limitada y caduca, los diferentes estudios que la abordan constatan, por otra parte, su interés. Entre los primeros estudios encontramos los de Christiane ChauletAchour (1990), Guy Dugas (1991), Jacques Dubois (1991), Alec Hargreaves (1992), Laronde (1993), Charles Bonn (1994), Jean Dejeux (1994) u Odile Cazenave (1996). No obstante nosotros nos centraremos en estudios posteriores que atienden a la literatura escrita por mujeres franco-magrebíes y su reconocimiento en el ámbito editorial, como los de Charles Bonn (2004), Josefina Bueno Alonso (2004), Fatiha el Galaï (2006), Nadia Châabane (2008), Vitali (2011), Bolduc (2011), Najib Redouane, \& Yvette Benayoun-Szmidt (2012, 2014), Samira Farhoud (2013), Beatriz Mangada Cañas (2014), Ríos Martínez (2015) o Schmidt (2016), entre otros. 


\section{Una cuestión de la identidad}

Uno de los problemas a los que se enfrenta esta segunda generación de francesas de padres norteafricanos es que, a pesar de haber nacido en Francia, siguen siendo consideradas extranjeras, inmigrantes o árabes. Esta estigmatización compromete su evolución social ya que afrontan múltiples dificultades sociales y económicas. La explicación a esta actitud, Philippe d'Iribane la encuentra en una arraigada estructura social asentada sobre el componente de clase:

La France reste un pays fondamentalement hiérarchique, attentif à ce qui distingue chacun de ses semblables selon mille critères, du caractère plus ou moins brillant de ses études à ses origines sociales, regionales, ethniques ou autres en passant par le métier qu'il exerce et le lieu où il demeure. (d'Iribane, 2010: 129)

Este sentir ha tenido un fuerte calado entre los jóvenes de esta generación, a lo que se une el interés de sus familias por mantener intactos los valores, la lengua, la cultura y la religión de sus ancestros, pese a su deseo de identificarse como miembros de la sociedad francesa. Ante tal situación, no es extraño que asuman su multiculturalidad y se definan franceses y árabes: “D’abord, pourquoi Maghrébins ? Ne sont-ils pas Français pour la plupart d'entre eux? Donc Franco-Maghrébins, c'est ainsi que nombre d'entre eux se revendiquent” (Belaskri, 2007: 13). Esta apelación de franco-magrebí marca su grado de asimilación al grupo dominante e indica el límite de concesiones con respecto a su integración.

La cuestión de la identidad está en el centro de la escritura de estas voces femeninas franco-magrebíes desde los años 90 hasta la actualidad. La falta de libertad, el conflicto identitario, la emancipación, aparecen como temática reiterada en las autoras beurs: Leila Houari, Zeida de nulle part (1985); Djura, Le Voile du silence (1990); Ferrudja Kessas, Beur 's Story (1990), Soraya Nini, Ils disent que je suis une beurette (1993), etc. Si la meta de las protagonistas está clara, los obstáculos y los rivales a los que se enfrentan son diversos y ambiguos. ¿Hay que romper los lazos con algunos individuos (padres/hermanos), con el modo de pensar (patriarcal), o con la sociedad al completo (el país de origen)? Las respuestas varían de un texto a otro.

En su novela autobiográfica Le voile du silence (1990), Djura relata las alegrías y las decepciones que han marcado la relación con sus padres, sobre todo su padre, quien supone el mayor obstáculo a las aspiraciones de la autora. Por su parte, Fatima, la hermana de Malika en Beur's story, ejemplifica la doble marginalidad a la que se enfrentan las niñas, tanto por su dualidad étnica como por su condición de género, al verse sometidas a la autoridad masculina en el espacio doméstico: 
Et puis, justement eux qui ont tant de problèmes, ils devraient nous comprendre, nous aussi nous sommes de la deuxième génération, un jour ou l'autre on sera peut-être confrontés à pire que ça! Et au lieu de nous donner la main, ils nous tournent le dos! Et faute de jouer les caïds dehors, ils les jouent chez eux! (Kessas, 1990: 202)

La reacción de las escritoras que conocieron de primera mano estas circunstancias fue exigir su derecho a la consideración de identidad única y no de l'entre-deux que les impedía su desarrollo social: "reconnues en tant que citoyennes à part entière et non pas, comme elles avaient souvent le sentiment désagréable, d'être cataloguées pour des citoyennes entièrement à part" (Redouane; Benayoun-Szmidt, 2012: 22). En cierto sentido se veían representadas en su apelativo franco-magrebí, pero rechazaban la política de victimización de la sociedad francesa por lo que optaron por abanderar un cambio a través de la emancipación y la autonomía mediante la formación académica.

Por otra parte, aunque esta problemática se mantenga en el encuentro de dos identidades, las actitudes de las autoras contemporáneas difieren de las de sus predecesoras, puesto que reclaman el derecho a ser reconocidas como francesas, aunque en su fuero interno tienen la firme convicción de que su obra se enriquece con la doble cultura que las representa, su alma francesa y su sensibilidad norteafricana (Olsson, 2011). Con esta nueva óptica, estas autoras consiguen dar a sus creaciones una noción de cultura con identidad propia, especial, que ha despertado un interés mediático, no solo en Francia sino a nivel mundial. De hecho, parece que algunas autoras gozan más de reconocimiento internacional que nacional, tal y como evidencia Laura Reeck a propósito del éxito de la primera novela de Faïza Guène, Kiffe kiffe demain: "[...] là où cette presse situe Guène dans un contexte et des référents littéraires et culturels, la presse française fait d'elle plus souvent un sujet des pages 'société' qu'un écrivain mentionné dans les pages 'culture' ou 'littérature'" (Reeck, 2012: 6).

Pese a ello, las autoras siguen rechazando su catalogación y propugnan el derecho a la diferencia. Así lo constata Soraya Nini en su obra de corte autobiográfico Ils disent que je suis une beurette en la que el título ya evidencia que no se reconoce en el apelativo beur/ beurette:

Je suis née au Paradis, et il paraît que je suis "une beurette", ça veut dire "une enfant d'immigrés". En tous les cas, moi, je sais que mon père et ma mère s'appellent Monsieur et madame Nalib, et que je suis leur fille. Cela m'est égal de savoir s'ils sont immigrés ou pas, l'essentiel c'est qu'ils soient mes parents. J'habite la cité HLM “Mon Paradis". (Nini, 1993: 9)

Sea como fuere, la producción de estas autoras adquiere una dimensión considerable ya que practican una escritura de inserción en la que evocan tanto su propia cultura como su deseo de pertenencia. Una escritura que se caracteriza por la continuidad, la ruptura, la 
innovación y la reformulación de nuevos temas. Esta variedad persigue un objetivo común que es la liberación y la construcción de su propio futuro, de ahí, como sostiene Siobhán McIlvanney, la necesidad de encontrar su propia voie/voix (camino/voz):

At this particular socio-historical juncture, narratives by beur women can be seen to occupy a 'third space', a space which, if not yet characterised by a nourishing transcultural reciprocity, none the less represents a form of liberation: having long had their identities contained in ideological straitjackets, the female narrators in these examples of beur women's writing signal the importance of finding their own voie/voix (way/ voice) for future representation. (McIlvanney, 2018: 138-139)

\section{Difícil tarea.}

Si bien el objetivo es común, las historias de los personajes que protagonizan sus novelas no van a optar por un itinerario homogéneo, ya que su actitud frente a esta situación va a ser poliédrica y no todas las caras son optimistas. Veamos a continuación diferentes posicionamientos y estrategias implementadas por algunas de las autoras que transcurren por sendas dispares.

a. Desarraigo. En la obra de Farida Belghoul, Georgette! (1986), la protagonista se enfrenta a múltiples discursos que quieren imponerle una identidad compleja, dual, bicultural y bilingüe. Sin embargo, esta protagonista cauta no se contenta con elegir entre los modelos que la escuela y la familia le exigen, ya que no encuentra su lugar ni en Francia ni en Argelia. Muy al contrario se muestra vigilante para no ceder a esos discursos que quieren convertirla en un elemento representativo de un grupo social determinado.

En una de las reflexiones que Georgette realiza de las películas de los "Indiens" y "cow-boy" que ve en la televisión, la protagonista se identifica con las estrategias adoptadas por los "Indiens", que consiste en disfrazar su identidad para que esta sea esquiva, elusiva: "Je ne suis pas une indienne! Je me déguise tous les matins, d'accord" (Belghoul, 1986: 81). Se trata por tanto de una estrategia de "dé-connaissance" (Rosello, 1993: 44), una identidad de no pertenencia ("n'être de nulle part").

Esta es también la actitud de Samia, protagonista de Ils disent que je suis une beurette, de Soraya Nini (1993), quien no logra hallar el lugar donde poder inventarse a sí misma, donde dejar de ser diferente, extranjera. Por un lado, para su entorno familiar la calle le está prohibida por ser mujer y, por otro, la escuela le recuerda que no es francesa, sin embargo, tampoco es argelina. En un pasaje, Samia narra el día en que la profesora le pidió que contara a los compañeros de clase cómo es Argelia, su país. Samia, abrumada, es incapaz de señalar a la profesora que Argelia es el país de sus padres: "Mais moi, j'arrive plus à parler, je prends la règle dans mes mains pour m'occuper. Ils attendent tous que je dise quelque chose, mais qu'est-ce que je peux dire sur l'Algérie? J'y ai jamais mis les pieds" (Nini, 1993: 27). Para 
evitar que situaciones similares se reproduzcan, Samia aprende a desaparecer literalmente: “Tout le monde vous regarde quand vous arrivez après, comme si vous n'étiez pas normal. Alors moi, je me fais encore plus petite pour qu'on me voie pas; ça marche [...]" (Nini, 1993: 21-22).

Sakina Boukhedenna proclama en Journal "Nationalité: immigré(e)" (1987): "C'est en France que j'ai appris à être Arabe/C'est en Algérie que j'ai appris à être l'Immigrée" (Boukhedenna, 1987: 5). En este diario, Sakina recoge un testimonio personal desde el 4 de julio de 1979 a 1980, en el que la autora hace partícipe al lector de su lucha vital por descubrir quién es.

Ardua empresa a la que se enfrenta igualmente Zeïda, la protagonista del relato de Leïla Houari, Zeïda de nulle part (1985), cuyo título deja entrever el resultado de la misma. Zeïda adopta enseguida su posicionamiento a propósito de su sentimiento de pertenencia y se lo deja claro al hombre que quiere conocerla en un bar porque ella es árabe: "Non je ne suis pas arabe, je ne suis rien, je suis moi" (Houari, 1985: 15).

La estrategia de Zeïda y Sakina recuerda la lógica del $n i / n i^{7}$, es decir, ni árabe ni francés, que se haya en la base de la identidad beur. En otro sentido, la lógica ni/ni puede igualmente transformarse en et/et creándose así un "tiers espace" (Ledoux-Beaugrand, 2005: 66) en el que articular una nueva identidad.

b. Huida. Dans Journal “Nationalité: immigré(e)”, Sakinna vaga por Francia, de ciudad en ciudad, luego por Argelia, sin encontrar un lugar en el que afianzarse. Pero la huida puede ser más dramática si cabe cuando huyen de sí mismas, de su cuerpo, de su vida. En Ce pays dont je meurs (1999) de Fawzia Zouari, los lectores somos testigos de una vertiginosa caída al abismo. Tras la muerte de sus padres, Nacéra y Amira se dejan arrastrar hacia la nada. Desde el principio la actitud de Nacéra deja entrever su objetivo: en Francia se siente fuera de lugar, lo único que desea es parecerse a los demás, hacerse pequeña, común, inexistente. La voluntad de Amira es ser aceptada como francesa de pleno derecho porque quiere disfrutar de la libertad que esta elección le ofrece, pero Francia no tiene interés alguno en ella. Igualmente se siente rechazada por su familia en Argelia, así que claudica y deja de comer. El desinterés se evidencia desde las primeras páginas cuando Nacéra, a modo de narradorprotagonista en primera persona, describe al lector la escena en la que la policía encuentra su cuerpo sin vida junto al de su hermana, en el suelo del apartamento, e incide en el silencio

7 Esta lógica $n i / n i$, de no pertenencia a ninguno de los dos contextos, no es exclusiva de los autores francomagrebíes; de hecho, parece una tendencia propia de segundas generaciones de inmigrantes de orígenes diversos. Salie, por ejemplo, la protagonista franco-senegalesa del relato de Fatou Diome Le ventre de l'Atlantique, (2003), al igual que las protagonistas franco-magrebíes, se siente excluida en ambos contextos, es "l'autre" en Francia (en Strasbourg, donde reside), y en su isla natal, convirtiéndose así en ciudadana del mundo: "Je cherche mon pays là où on apprécie l'être additionné, sans dissocier ses multiples strates. Je cherche mon pays là où s'estompe la fragmentation identitaire [...] Alors, partout où je pose mes valises, je suis chez moi" (Diome, 2003: 296). 
de los vecinos y la actitud de la policía, poco motivada en buscar la causa de sus muertes: “À quoi peuvent succomber deux jeunes femmes de vingt-six et trente-trois ans aujourd'hui? Overdose probablement” (Zouari, 1999: 11).

Farida Belghoul representa una doble huida en Georgette! (1986): física, al final de la novela cuando toma la decisión de no ir al colegio y recorrer las calles; y metafórica, cuando en clase se evade con la imaginación y vaga por paisajes y escenas de su pasado.

c. Fingimiento. Si la "départenance" (Rosello, 1996: 205) consiste en un doble alejamiento, el fingimiento es también una estrategia de la dualidad, pero, en este caso, es fingir la doble pertenencia, adoptar una imagen en el entorno familiar y otra diferente en el mundo exterior. Se trata por tanto de una estrategia basada en el engaño y la mentira, características innatas a la identidad de la literatura beur que, según Vallet, Nehas y Sghiri (1996: 77) "est multiforme en ce qu'elle se construit selon le contexte social [...] et montre que les romans beurs présentent une récurrence du théâtral [...] qui s'articule autour de motifs comme le jeu, le déguisement, le masque et le mensonge".

Estos motivos los reconocemos en la novela Georgette! y representan la táctica de resistencia por excelencia de la protagonista. Con el fin de escapar de las identidades que quieren imponerle, ella elige construir falsas identidades para engañar a los que la rodean. El disimulo es por tanto una estrategia defensiva:

Je suis un petit chat sauvage qui se voit pas. Je me planque derrière un masque sur la
figure [...]. Les gens sont tous jaloux de ma beauté. Ils devinent pas que c'est une ruse
[...] J'ai un masque de beauté sur le visage c'est une ruse de guerre. (Belghoul, 1986:
76-77)

El fingimiento se pone de manifiesto bien asumiendo el papel de otra persona, convirtiéndose en otra persona, bien copiando el comportamiento de los que están alrededor. La copia es la estrategia que elige Nina, en la obra Garçon manqué (2008), para ser a la vez argelina y francesa, y encontrar su lugar en casa y en la sociedad. Para ella la nacionalidad es un papel que se puede representar "J'imite" (Bouraoui, 2008: 9).

d. Asimilación. La protagonista de Anne ici, Sélima là-bas, novela de Marie Féraud (1982), es una joven francesa de origen magrebí que vive en la banlieue marsellesa y que cambia su nombre Sélima por Anne para lograr la integración y una identidad francesa. De este modo toma partido por una de sus dos mitades: “Je savais qu'Anne m'aiderait à m'intégrer" (Féraud, 1982: 16).

No es extraño que las protagonistas que persiguen la integración deseen cambiar sus nombres. Shérazade, la protagonista de la obra homónima de Sebbar (1982), confiesa que cuando dice su nombre los chicos piensan en las mil y una noches, no se creen que sea su verdadero nombre, no lo ven como un nombre de verdad. 
En todos estos textos, y en general en las obras de las autoras beurs, las hermanas están mejor educadas y se desenvuelven con más soltura en la escuela que sus hermanos debido a su percepción de la educación como un medio para ampliar las limitadas oportunidades de su cultura doméstica. El futuro al que las enfrenta su cultura de origen, que las entierra en un matrimonio concertado, es el sometimiento y la anulación. Así lo explica Sakinna en Journal "Nationalité: immigrée":

Nos hommes disent que nous, les femmes immigrées de la deuxième génération, nous ne sommes plus des vraies Arabes car nous sommes comme les Européennes. [...] Comme si la femme arabe, à leurs yeux voulait dire: maison, chiffon, enfant et ferme ta gueule. (Boukhedenna, 1987: 93)

La formación por tanto es el medio de transformación social. Gracias a ella, Dunia, la hermana de Mourad, en Un homme, ça ne pleure pas (2014) de Faïza Guène, se convierte en una abogada de prestigio y entra en política:

Ma sœur devenait un symbole. Invitée à donner son avis sur tous les sujets, elle s'exprimait avec un brio et un aplomb à peine croyables. La petite élue arabe de province était en passe de devenir la nouvelle coqueluche de l'élite parisienne. (Guène, 2014: 69)

Dunia ha optado por la asimilación, por su identidad francesa, ha cambiado de nombre y de aspecto físico: "En somme, un groupe de Julie Guérin d'une vingtaine d'années qui avait aidé ma sœur à révéler la Christine qui sommeillait en elle" (Guène, 2014: 22). Misma estrategia es la de Amira, hermana menor de Nacéra en Ce pays dont je meurs (1999), que para ser aceptada en el colegio se hace llamar Marie y se inventa unos orígenes italianos.

e. Aceptación. En el relato de Jeanne Benameur, Samira des quatre-routes (1992), Samira, la protagonista, no quiere renunciar a las oportunidades que su país de acogida le ofrece y se pregunta por qué, para no traicionar a la cultura de sus padres, debe claudicar. Ante esta tesitura opta por la tolerancia, la aceptación: “j'apprendrai à mes enfants à respecter toutes les cultures et à aimer" (Benameur, 1992: 103). Mismo posicionamiento es el que adopta Aïcha Benaïssa en su autobiografía Née en France (1990), como vemos en esta cita: "être soi-même, être française sans renoncer à ses racines" (Benaïssa, 1990, citado en Panaïté, 2012: 33).

Entre-deux Je: Algérienne? Française? Comment choisir... (2001) es el testimonio de Souâd Belhaddad sobre la dificultad de ser uno mismo cuando el ser se halla entre dos identidades. Belhaddad opta por la libertad y un compromiso inquebrantable a favor de los derechos humanos. Esta toma de posición no le impide denunciar el trato injusto del que fue 
víctima en su infancia, del mismo modo que las injusticias, el racismo y el antisemitismo que horadan la sociedad francesa.

Nora Merniz se sitúa en el entre-deux. En el relato autobiográfico Famille nombreuse (2002) se adhiere a su identidad francesa pero no reniega de su herencia familiar ni de su pertenencia a una familia de argelinos en Francia.

f. Integración y liberación. En Tafami (1998), de Fatima Nouri, la protagonista retrata recuerdos de su infancia y adolescencia en una espiral de autodestrucción. No obstante, a medida que progresa esta autobiografía, la depresión muta hacia la liberación y la esperanza. Según Najib Redouane, en esta obra 'l’intégration n'est plus un questionnement mais une évidence" (Redouane, 2014: 26).

En Kiffe kiffe demain (2004), Faïza Guène denuncia que las mujeres de la banlieue no solo son víctimas del patriarcado doméstico unido al fundamentalismo religioso, sino que también son objeto de una explotación económica que va más allá de las especificidades culturales y étnicas de su entorno. La fuerza de la narración radica en la exploración de los defectos de estos sistemas de explotación y las respuestas a través de la estrecha relación madre-hija.

El abandono de su padre se transforma en oportunidad en la medida en que permite el establecimiento de una unidad familiar exclusivamente femenina y el desarrollo de una relación madre-hija que no sufre ninguna interferencia familiar. La oportunidad de avanzar también es entendida en esta obra a través de la formación académica: "Maman, elle va suivre une formation d'alphabétisation. On va lui apprendre à lire et à écrire la langue de mon pays" (Guène, 2004: 80). Como vemos, Doria se siente integrada en Francia.

No queremos cerrar este apartado sin hacer alusión a que este posicionamiento ilusionante y optimista de Guène abre una vía esperanzadora no solo a las protagonistas de esta historia sino a toda una comunidad femenina de banlieue:

Moi, je mènerai la révolte de la cité du Paradis [...]. Mais ce ne sera pas une révolte comme dans le film La Haine où ça se finit pas hyper bien. Ce sera une révolte intelligente, sans aucune violence, où on se soulèvera pour être reconnus, tous. Y a pas que le rap et le foot dans la vie. (Guène, 2004: 189)

El mensaje es muy simple: cada reto es una posibilidad de avanzar hacia algo mejor.

De las estrategias que acabamos de presentar extraemos varias constataciones. En primer lugar, dado que la reivindicación de una identidad colectiva definida por el movimiento beur ha fracasado al no ofrecer a la comunidad femenina una identidad que le haga justicia, esta se ha visto en la necesidad de definirse a sí misma. Algunas han optado por vivir sin identidad, otras l'entre-deux, o bien una filosofía $n i / n i$, otras han adoptado la postura cama- 
leónica del fingimiento, e incluso la autodestrucción. En segundo lugar, gracias a la literatura, las autoras de segunda generación tratan de encontrarse y definirse a sí mismas evitando catalogaciones ajenas. De este modo logran romper el silencio impuesto abordando temas complejos para la sociedad occidental como el racismo y la exclusión.

\section{Recursos narrativos del imaginario femenino de femme française issue de l'immigration}

Una de las características más notables de la literatura de segunda generación es el prisma autobiográfico de sus relatos. Ya sea narrados en primera persona o en tercera, la óptica autobiográfica y documental les confieren el estatus de littérature de témoignage. Si, como acabamos de ver, estas autoras quieren dejar constancia de su exclusión, de sus conflictos identitarios y su sometimiento, tiene sentido la adopción de esta técnica cuya función predominante es informativa. No obstante, podría atribuírsele además la función terapéutica que ayudaría a las autoras en la búsqueda de su identidad.

Philippe Lejeune (1975: 14) define la autobiografía como "récit rétrospectif en prose qu'une personne réelle fait de sa propre existence, lorsqu'elle met l'accent sur sa vie individuelle, en particulier sur l'histoire de sa personnalité". En este sentido la autobiografía es un relato de hechos concretos del pasado del autor, cuyos personajes son reales. Lejeune afirma, asimismo, que existen varios factores que determinan este tipo de narrativa, como el escenario de la misma, su carácter unitario, la fidelidad, la coherencia y el pacto autobiográfico. Su forma convencional es por tanto aquella en la que el narrador-autor describe el mundo tal y como lo ve.

Pero ¿qué motiva a las autoras a elegir un material autobiográfico? Convenimos con Meriem Hamza que se debe a la necesidad de afirmar una identidad liberada a través de una literatura intimista expresada en primera persona "une enquête du soi ou une renaissance d'une identité féminine" (Hamza, 2014: 28). Un ejemplo de esta técnica la encontramos en Journal: "Nationalité: Immigrée" de Sakinna Boukhedenna, donde se produce un "pacte autobiographique" (Lejeune, 1975) real, mediante la asimilación del nombre de la autora con el de protagonista. Pero no siempre esta asimilación es tan evidente, de hecho, es más frecuente que las autoras eviten ser confundidas con las narradoras, como en La Scalera, de Fatima Bakhaï o en La voyeuse interdite de Nina Bouraoui.

En Beur's story, texto también escrito en tercera persona, nada indica que se trate de un texto autobiográfico, salvo por la dedicatoria "Je dédie cette histoire à mes sœurs maghrébines pour que nous cessions d'être cette entité négligeable qui hante l'arrière-plan des romans de nos jeunes écrivains maghrébins" (Kessas, 1990: 7). Se trata pues de un texto heterodiegético ya que el narrador no desempeña papel alguno en la historia. Pese a que pue- 
da ser confundido con el personaje de Malika, el narrador es omnisciente y relata pasajes que escapan al conocimiento de Malika. En otros casos, como en Zeïda de nulle part, de Leïla Houari, encontramos cierta alternancia entre el sujeto en primera persona del singular (je) y de tercera persona del singular (elle). Este fenómeno se debe, según Gontard, a “l’expérience du déracinement" (Gontard, 1991: 108).

Las escritoras más actuales como Faïza Guène y Nina Bouraoui recurren a un narrador que se expresa en primera persona; como en Garçon manqué, en que la autora/narradora habla en primera persona de su vida familiar e íntima. En cuanto a Faïza Guène, aunque sus novelas no se consideran autobiográficas, la identidad cultural y geográfica de las protagonistas de Kiffe kiffe demain y Du rêve pour les oufs, Doria y Alhème respectivamente, nos hace pensar en un paralelismo con su condición de hija de inmigrantes residente en una banlieue. El primer relato, Kiffe kiffe demain es un monólogo interior en el que Doria, una joven de 15 años, nos relata la evolución de sus pensamientos. La novela mantiene un estatus autodiegético, la narradora se funde lingüística y psicológicamente en el discurso del personaje, sin embargo, Guène confiesa que el único vínculo que le une a Doria es la pasión por la televisión: "Mon livre n'a rien d'autobiographique dans les faits. Je rejoins mon personnage sur sa culture tv en béton armé” (Ceia-Minjares, 2007: 95).

Otro rasgo característico de la literatura beur femenina es el uso de la lengua francesa. El francés representa un sello de pertenencia para estas autoras, constituye una herramienta que les permite luchar contra cualquier forma de exclusión, con la finalidad de despertar conciencias. De este modo lo justifica Malika Mokeddem:

La langue française en m'apportant les rébellions, pas uniquement des autres en tant que Français, mais des autres continents; Dickens, Tolstoï, Faulkner, Dostoïevski, etc., [...] le français m'a appris à me défendre, pas seulement à crier. (Helm, 2000: 42)

Se trata de una lengua vehicular y mestiza enriquecida con expresiones argóticas, términos árabes y una oralidad fingida que retrata la lengua hablada.

En los primeros textos, el estilo oral venía a testimoniar de forma realista el modo de vida de los franceses de origen magrebí en la periferia. Por ejemplo apreciamos en la obra de Belghoul la transcripción del habla de sus padres en su forma oral, con particularidades sintácticas y de pronunciación. Este recurso podría entenderse como un signo reivindicativo: dar voz a la generación de padres que venidos del Magreb se ven abocados a las periferias geográficas y sociales y también al silencio por su analfabetismo. En los siguientes ejemplos notamos las omisiones y el registro vulgar del padre de Georgette: "Si c'voyou, se lève pas, j'suis plus son père. J'le jette dans la rue" (Belghoul, 1986: 50), o el zezeo de Mireille "Elle m'embrasse très fort. -Zis-moi, zis-moi!" (Belghoul, 1986: 37).

El relato de Kessas, Beur's story, está salpicado de palabras malsonantes y expresiones coloquiales: "Bah! alors on peut plus roupiller dans cette baraque? Et pourquoi tout ce 
boucan! Bordel de merde!” (Kessas, 1990: 136). Con este comentario Slimane, el hermano de Malika se queja de que la charla de su madre y hermanas no le deja dormir. Asimismo, se recrean los errores de pronunciación de personajes de origen magrebí cuando hablan francés. En el siguiente ejemplo un trabajador piropea a Farida y Malika: "Coucou, pitite dimouaselles, ti te promine!" (Kessas, 1990: 15).

Las escritoras más contemporáneas utilizan el argot como estrategia de comunicación, por su función identitaria de afirmación y protesta. De hecho, al comienzo de su obra Kiffe kiffe demain, Guène afirma que sus personajes hacen un remix de la lengua de Molière: "fait des remix de la langue de Molière" (Guène, 2004: 39). De este modo transforma el verlan de banlieue en capital literario, convierte un estigma social en recurso lingüístico-literario. Múltiples términos argóticos salpican todo el relato: bouffer (manger), enfoiré (déloyal), pédale (homosexuel), gonzesse (fille), zonzon (prison), pote (ami), etc., así como las construcciones verlanizadas en las que se incluyen términos que han alterado el orden de sus sílabas: "Il a

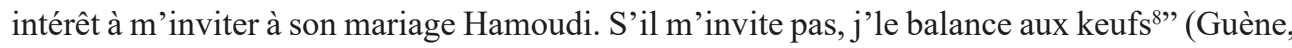
2004: 165).

También son frecuentes los préstamos del inglés: deal (vendeur de drogue), joint (cigarette de haschisch), sex-shops (magasin de sexe), etc.; o del árabe: “C'est le lendemain de l'aïd, la fête du Mouton" (Guène, 2004: 90); “pour qu'on voie mes yeux, maman me les a entourés de khôl” (Guène, 2004: 157); “C'est fini, c'est plus kif-kif demain comme tu disais à tout le monde?" (Guène, 2004: 187).

Otros recursos son las apócopes (ciné, photo, etc.), y algunas menos clásicas como frrre (frère), gr (grand); la derivación con sufijos -ard,(conard) -asse (connasse), etc. Sin obviar algunas modificaciones sintácticas como la omisión de la partícula negativa ne y del pronombre sujeto $i l$, o la alteración de reglas gramaticales: “Si j'aurais su, j'aurais même pas eu mes règles" (Guène, 2004: 85).

El lenguaje grosero o vulgar tiene cabida igualmente pero siempre envuelto en un halo humorístico o irónico. Así se expresa Doria a propósito de un libro: “Le bouquin s'il te prend l'envie de le lire dans le métro, t'as intérêt à le couvrir de papier kraft, sinon le gros Francis qui lit Le Figaro, tout fier, la bouche ouverte avec un putain d'air supérieur, il risque de bien se foutre de ta gueule" (Guène, 2004: 57).

Pero este modo de expresión no es gratuito, es la voz de un grupo social en un contexto espacio-temporal preciso. Es lo que Bulot denomina "territorialisation" (2006: 40) de una variedad de lengua en el espacio de la banlieue. De hecho, el espacio es tan determinante que otorga el nombre, a partir de los años 2000, a esta ficción narrativa: littérature de banlieue, denominación que disgusta al colectivo literario que lo integra y que queda reflejado en el manifiesto firmado en 2007 por los autores que componen el grupo Qui fait la France?, entre los que se encuentran Faïza Guène y Habiba Mahaby ${ }^{9}$.

8 Keuf hace referencia a flic, agent de police.

9 Otros autores que representan este grupo son Mohamed Razane, Karim Amellal, Jean-Eric Boulin, Thomte 
En otro sentido, el espacio doméstico es igualmente coercitivo para madres e hijas, en él el hombre impone su autoridad: "Ça suffit maintenant! décréta Monsieur Azouik. Va nous faire du café, ça te calmera” (Kessas, 1990: 199). En la siguiente cita, Malika soporta la amenaza de su hermano: “D'ailleurs c'est simple, si j'apprends la moindre aventure qui vienne de toi ou de Fatima, je vous casse en deux" (Kessas, 1990: 37).

Frente a este panorama, las jóvenes de segunda generación se acercan al espacio escolar, porque para ellas la formación constituye la oportunidad de asegurarse un futuro mejor: "Elle savait que ses études étaient son seul et unique moyen de voir un jour se profiler des horizons nouveaux" (Kessas, 1990: 200). No obstante, encuentran la oposición de los padres que se sienten intimidados por una institución educativa que les resta poder y les roba a sus hijas. Aicha, la protagonista de Née en France, es consciente de que solo alcanzará su autonomía con la educación: "J'avais décidé que ce qui importait avant tout, c'était la poursuite de mes études" (Benaissa, 1990: 28).

Los relatos más recientes constatan que el éxito y la libertad se alcanzan mediante la alfabetización y el estudio. Es el caso de dos de los personajes de Guène: Dunia, en Un homme, ça ne pleure pas (2014), tras su paso por la universidad se convierte en una abogada de prestigio; y Doria y su madre encuentran en el estudio la motivación e ilusión necesarias para salir adelante ellas solas.

En otro sentido, el espacio metafórico de la escritura representa un universo de libertad. Este espacio liberador se materializa, por ejemplo, en Sebbar, en la biblioteca. De este modo se expresa el narrador en Shérazade, 17 ans, brune, frisée, les yeux verts:

D'ailleurs de plus en plus de jeunes Maghrébines de l'immigration venaient à la bibliothèque, et pas seulement pour échapper à la surveillance familiale. Elles se rencontraient, bavardaient, lisaient, choisissaient les livres ensemble, feuilletaient les journaux [...]. (Sebbar, 1982: 97)

Samia, la protagonista de Ils disent que je suis une beurette, encuentra el poder de la escritura gracias a la motivación de su profesora Mme Sallibert: “C'est en français que je m'en sors le mieux. Il est même arrivé que Madame Sallibert lise mon devoir devant toute la classe" (Nini, 1993: 130).

Al igual que sus protagonistas, para las autoras issues de l'immigration la actividad creadora se concibe como una liberación, un espacio privado reservado a la mujer, frente a ese espacio público, que por tradición se les concede a los hombres.

Ryam, Dembo Goumane, Samir Ouazene, Mabrouck Rachedi o Khalid el Bahji. 


\section{Reconocimiento editorial de la literatura femenina franco-magrebí}

De las obras presentadas en este estudio, el reconocimiento editorial ha sido muy dispar. Las diferentes lecturas que hemos llevado a cabo sobre estas literaturas nos permiten determinar las líneas de actuación y posicionamiento por parte de la crítica, y que desarrollamos en este espacio.

La literatura beur, desde sus inicios, se ha hallado en una posición desfavorable con respecto a otras expresiones literarias al adquirir pronto la etiqueta de littérature mineure. Los argumentos esbozados redundan en la escasa calidad literaria "leur valeur littéraire [...] n'a pour le moment rien de transcendant" (Djaout, 1991: 158), la falta de criterio estético, la simpleza de una narración autobiográfica y el interés por subrayar la hibridez cultural. De hecho, para las casas de edición el atractivo de estos relatos se reduce a su valor sociológico y no literario, de modo que, en algunos casos, reconocemos en el éxito de una u otra novela más un logro de reinserción del autor que una creación literaria. Pero a medida que esta expresión literaria evoluciona, abandona su posicionamiento miserabilista, incorpora un trabajo más ficcional y menos autobiográfico, mayor riqueza lingüística, de modo que los autores comienzan a llamar la atención de las casas de edición y de los medios de comunicación. A este panorama se une la reivindicación de igualdad e inclusión en el campo literario francés de estos autores, que aunque de orígenes diferentes nacieron en Francia: "Parce que catalogués écrivains de banlieues, étymologiquement le lieu du ban, nous voulons investir le champ culturel, transcender les frontières et ainsi récupérer l'espace confisqué qui nous revient de droit, pour l'aspiration légitime à l'universalisme" (Reeck, 2012: 5).

En cuanto a la recepción de textos de escritoras franco-magrebíes, tienen que sufrir otra marginación, resultado directo de una concepción tradicional de la crítica literaria que pretende relegar la contribución femenina a una categoría muy específica en comparación con la producción masculina. La diversificación de sus escritos se denomina "Écritures féminines de l'immigration", "l'écriture féminine de l'immigration maghrébine en France", "l'écriture des Maghrébines en France", etc. y pocas son recompensadas con premios literarios de renombre, apenas Nina Bouaraoui, Prix du Livre Inter (1991) por la Voyageuse interdite y Prix Renaudot (2005) por Mes mauvaises pensées; Houda Rouane, Prix Première (2007), por Pieds-blancs; o Kaoutar Harchi, Prix de la Société des Gens de Lettres y Prix Thyde Monnier (2011) por L'Ampleur du saccage. De hecho, en una entrevista a Faïza Guène, realizada por el periódico The Guardian (2008) tras el éxito de Kiffe, kiffe demain (2004), al preguntarle por sus opciones de obtener un premio, responde que la crítica literaria francesa no se interesa por la banlieue: 
Les grands prix littéraires? Vous plaisantez? Jamais, de toute ma vie, jamais, je ne gagnerai un prix littéraire. Cela voudrait dire que j'écris de la littérature et qu'il y a des intellectuels dans les banlieues. C'est justement là-dessus que rien ne change et que cette vision néocolonialiste s'exprime... Les indigènes savent faire du sport, chanter et danser, mais ils ne peuvent pas penser. (Chrisafis, 2008)

Muchas autoras actuales son casi desconocidas para la crítica, y cuando despiertan el interés de las casas editoriales, deben someterse a estrategias comerciales que no siempre comparten. Soraya Nini, por ejemplo, tuvo que acceptar las exigencias de Fixot, su editorial, que no aprobó el título que propuso para su historia. La autora quería que su relato se titulara L'entre-deux, pero Fixot propuso el título La Beurette, lo que implicaba muchas imágenes estereotipadas. Finalmente se adoptó el título Ils disent que je suis une beurette que le convenía a Fixot y permitió a Nini evitar la etiqueta beur.

Sin embargo, pese al rechazo de la crítica en torno a estas expresiones literarias interculturales, poco a poco el apoyo por parte de las instituciones comienza a ser una realidad y se fomenta la inclusión de las obras literarias beurs en los programas escolares de Francia (Vitali, 2011), porque a tenor de la diversidad cultural que hay en este país y la tasa de fracaso escolar entre los hijos de inmigrantes en general, estas obras ayudan a la convivencia, y sus autores sirven de referente a los niños que experimentan una situación socio-cultural similar. Un ejemplo ilustrativo de estos argumentos es la siguiente cita de Petrescu:

[...] l'effet social qu'un écrivain "beur" peut avoir parmi les siens se manifeste sous deux aspects chez les élèves. D'un côté, par l'exemple personnel il peut stimuler leur succès scolaire et leur intégration sociale... D'un autre côté, le roman "beur" peut devenir un outil pédagogique. (Petrescu, 2010: 114)

\section{Conclusiones}

La denominación littérature beur es la expresión de un cambio social en la Francia metropolitana gracias en especial a la diversificación de su población. Nuevas etnias, religiones, culturas, lenguas se vieron abocadas a cohabitar, no siempre en las mejores condiciones, lo que redundó en conflictos sociales y reivindicación de derechos civiles. La multiculturalidad no entendida entraña discriminación y perjudica la integración, y en la esfera privada se traduce en cuestionamiento identitario. Las autoras que inician su andadura en los años 80 del pasado siglo quisieron dejar constancia de esta ebullición sociocultural y cómo afectaba a un colectivo tradicionalmente denostado y perjudicado por todos los órganos de poder, institucionales, familiares, culturales o sociales, como es el colectivo femenino.

Estas escritoras recogieron el testimonio, en primera persona, de esposas, madres, hijas, llegadas a Francia desde el norte de África o nacidas en el país galo, y dibujaron su realidad y su cotidianeidad. En sus obras, las autoras alzaron la voz para dejar constancia de 
su falta de libertad, de la violencia, el racismo o la opresión que soportaban en los espacios público y privado. Si bien es cierto que la realidad de los primeros escritos de autoras como Farida Belghoul o Leïla Sebbar no se corresponde con las autoras más contemporáneas, sus obras abrieron el camino a expresiones literarias proteiformes que reflejan las preocupaciones y cuestionamientos de la mujer francesa de segunda generación o issue de l'immigration. Una inquietud omnipresente en sus obras es el conflicto identitario. Sus reflexiones y posicionamientos constituyen vehículos eficaces para la deconstrucción del yo racial y sexual impuesto por la sociedad francesa contemporánea y serán defendidos por las protagonistas y heroínas de sus novelas, y que, como hemos visto, pasan por el desarraigo, la huida, el fingimiento, la asimilación, la aceptación, la integración y liberación. De un modo u otro, se trata de romper el silencio, de defenderse contra los poderes establecidos que las anulan, de sensibilizar a los lectores de las dificultades sufridas por este grupo social tan vulnerable, y el medio más idóneo que encuentran para ello es su voz, su escritura, el único contrapoder que les otorgan su dignidad y su libertad. Un poder que ellas convierten en arte, tal y como afirma la siguiente cita de Boinard Boisson y Aragón Ronsano con la que concluimos este trabajo:

[...] l'acte créatif dont il est question a la finalité de proclamer les souffrances des femmes qui vivent cette situation de l'entre-deux. Pourtant haïr n'est pas l'objectif, sinon la prise de conscience de l'absurde, de l'inacceptable: le courage est le seul témoignage possible et nécessaire pour les femmes. Ces voix qui s'expriment ont choisi de dire ce qui ne peut plus être, de faire vivre dans leur récit ce que les hommes et les femmes n'osent avouer. C'est un art qu'elles ont choisi d'honorer, un art où se résument à la fois le désir, la peur, la joie et la souffrance, un art qui doit nous servir: l'art de la vie. (Boisson \& Ronsano, 2007: 12)

\section{Referencias bibliográficas}

AMELlaL, Karim. 2014. “Ecrivains français d'origine maghrébine dans la décennie 2000: une littérature du décentrement" in LIMAG.com. Littérature du Maghreb. Communication au colloque "Langues et identités des écrivains méditerranéens francophones de la diaspora", Crasc, Oran, 16-17 décembre 2014: <https://n9.cl/znfu> [12/04/2021].

AmnaY, Idir. 2006. "Malika Mokeddem écrivaine 'l'acte d'écriture est ma première liberté", in El Watan, culture, 12 septembre 2006, 34-56.

Begag, Azouz. 1999. "Écritures marginales en France. Être écrivain d'origine maghrébine" in Tangence, 59, 62-69.

Belaskri, Yahia. 2007. "De l'immigré algérien au Franco-Maghrébin” in Yahia Belaskri (s. la dir. de). Les Franco-Maghrébins et la République. Paris-Méditérranée, Éditions APCV.

Belghoul, Farida. 1986. Georgette! Paris, Barrault.

BenaïssA, Aïcha. 1990. Née en France. Histoire d'une jeune beur. Paris, Éditions Payot.

Benameur, Jeanne. 1992. Samira des quatre routes. Paris, Flammarion. 
BoeHmer, Elleke. 2005. Stories of Women, Gender and Narrative in the Postcolonial Nation. Manchester and New York, Manchester University Press.

Boidard Boisson, María Cristina; Aragon Ronsano, Flavia. 2007. "Ce pays dont je meurs de Fawzia Zauari et L'année de l'éclipse de Fatima Ben Mansour: deux rencontres créatives sur l'immigration maghrébine" in Dominique Bonnet, María José Chaves García, Nadia Duchêne (coords.). Littérature, langages et arts. Rencontres et création. Universidad de Huelva (col. Collectánea, 112), 124-132.

Bolduc, Lucie. 2011. Construction identitaire dans la littérature Beure: L'exemple de Georgette! de Farida Belghoul. Trabajo de Fin de Máster dirigido por Martine Delvaux. Université de Québec (Montréal): <https://archipel.uqam.ca/4454/1/M12402.pdf> [15/04/2020].

Bonn, Charles. 1994. "Romans féminins de l'immigration maghrébine en France et en Belgique" in Notre librairie, 118, Juillet-Septembre, 98-107.

Bonn, Charles. 2001. "L'exil et la quête d'identité, fausses portes pour une approche des littératures de l'immigration?" in GAFAITI, Hafid, Cultures transnationales de France des “Beurs" aux...? Paris, L'Harmattan, 37-54: <https://n9.cl/74lp> [11/03/2021].

Bouhayat, Souad. 2017. Transgressions: corps féminin, langue d'adoption et légitimation dans la littérature maghrébine. Graduate Theses and Dissertations. Major Professor Jennifer Cazenave. University of South Florida: <http://scholarcommons.usf.edu/etd/6682> $[12 / 03 / 2021]$.

Boukhedenna, Sakina. 1987. Journal “Nationalité: immigré(e)”. Paris, L’Harmattan.

Bouraoui, Nina. 2019. Krivian, Astrid “'Écrire, c'est résister', interview à Nina Bouraoui”" in Afrique Magazine, avril 2019: <https://bit.ly/2SFr09L > [18/03/2021].

Bouraoui, Nina. 2008 [2000]. Garçon manqué. Paris, Stock.

Bueno Alonso, Josefina. 2004. "Femme, identité, écriture dans les textes francophones du Maghreb" in Thélème. Revista Complutense de Estudios Franceses, 19, 7-20: < https://bit. ly/30JLyT5> [12/05/2021].

Bulot, Thierry. 2006. Langue vivante, l’identité sociolinguistique des Cauchois. Paris, L'Harmattan.

Cazenave, Odile. 1996. Femmes rebelles. Naissance d'un nouveau roman africain au féminin. Paris, Khartala.

Ceia-Minjares, Laura. 2007. "Dj Zaïfe: remix de la cité du Paradis: interview avec Faïza Guène, écrivaine" in Contemporary French and Francophone Studies, 11(1), January: $<$ https://bit.ly/2SFcuij $>$ [12/05/2021].

Chaabane, Nadia. 2008. "Diversité des mouvements de "femmes dans l'immigration"” in Les cahiers du CEDREF. Centre d'enseignement, d'études et de recherches pour les études féministes, 16, 231-250: <https://journals.openedition.org/cedref/60> [16/04/2021].

Chaulet-Achour, Christiane. 1999a. Noûn. Algériennes dans l'écriture. Paris, Séguier.

Chaulet-Achour, Christiane. 1999b. L'Anthologie de la littérature algérienne de langue française. Paris, ENAP- Bordas. 
Cixous, Hélène. 1986. La venue à l'écriture. Paris, Des Femmes.

Chrisafis, Angelique. 2008. "Jamais ils ne me donneront de prix littéraire" in The Guardien, culture le 18 juin 2008: <https://bit.ly/2YY2aFs > [20/02/2021].

Dejeux, Jean. 1992. La littérature maghrébine d'expression française. Paris, Presses Universitaires de France.

DeJeux, Jean. 1994. La littérature féminine de langue française au Maghreb. Paris, Karthala.

Deleuze, Gilles; Guattari, Félix. 1975. Kafka. Pour une littérature mineure. Paris, Les Editions de Minuit.

DesPlanques, François. 1991. "Quand les Beurs prennent la plume” in Revue européenne de migrations internationales, 3, 139-152.

Detrez, Christine. 2010. "L'écriture comme résistance quotidienne: être écrivaine en Algérie et au Maroc aujourd'hui" in Sociétés contemporaines, 78(2), 65-85.

DidIER, Béatrice. 1981. L'écriture-femme. Paris, Éditions PUF (coll. Écriture).

Diome, Fatou. 2003. Le Ventre de l'Atlantique. Paris, Hachette.

D'IrIBARne, Philippe. 2010. Les Immigrés de la République. Impasses du multiculturalisme. Paris, Éditions du Seuil.

Djaout, Tahar. 1991. "Une écriture au 'beur' noir” in Itinéraires et contacts de cultures, 14, 156-158.

Donadey, Anne. 2001. Recasting Postcolonialism. Women Writing Between Worlds. Portsmouth, Heinemann.

Doubrovsky, Serge. 1977. Fils. Paris, Édition Galilée.

Dubois, Jacques. 1991. "En finir avec la marginalité" in Lise Gauvin et Jean-Marie Klienkenberg (dir.), Ecrivain cherche lecteur: L'écrivain francophone et ses publics. Paris, Éditions Creaphis, 119-129.

DugAs, Guy. 1991. "Francophonie, acculturation, littératures nationales et dominées. Retour sur quelques concepts mal définis" in Convergences et divergences dans les littératures francophones, Actas de coloquio de Nanterre, Paris, L'Harmattan, 15-21.

FARHOUD, Samira. 2013. Interventions autobiographiques des femmes du Maghreb: Écriture de contestation. New York, Peter Lang.

Feraud, Marie. 1982. Anne ici Sélima là-bas. Paris-Gembloux, Duculot.

Gadant, Monique. 1984. "La littérature immigrée" in Les Temps modernes, 452, mars-mai, 1988-1999.

GAfaÏTi, Hafid \& Arnelle Crouzieres-IGenthron. 2005. Femmes et écriture de la transgression. Paris, L'Harmattan.

Goes, Jan. 2003. "Littératures francophones du monde arabe -2- La littérature 'beur"” in 
Anales de Filología Francesa, n. ${ }^{\circ}$ 29, 2021

SOLEDAD DÍAZ ALARCÓN

Overgenomen uit Romaniac, 90, $1^{\mathrm{e}}$ trimestre, 1-8: <https://www.vlrom.be/pdf/032goes2. pdf $>[12 / 04 / 2021]$.

Gontard, Marc. 1991. "Marocaines de l'extérieur et de l'intérieur: Leïla Houari/Noufissa Sbai" in Plurial, 2, 107-108.

Gontard, Marc. 2005. Le récit féminin au Maroc. Paris, Plurial.

GRASSIN, Jean-Marie. 1999. "L'émergence des identités francophones le problème théorique et méthodologique" in Christiane Albert (dir.) Francophonie et identités culturelles, Paris, Karthala, 301-314.

Guene, Faïza. 2004. Kiffe kiffe demain. Paris, Hachette Littératures.

Hamza, Meriem. 2014. L'exil et le retour au pays natal dans L'interdite de Malika Mokeddem. Trabajo de Fin de Master dirigido por Karima Bouchène. Université Larbi Ben M'Hidi Oum El Bouaghi (Algérie): <https://n9.cl/486d > [14/03/2021].

HargreaVes, Alec G. 1992. La littérature beur. Un guide bio-bibliographique. New Orleans, Clefan Edition Monographs.

Hargreaves, Alec G. 1993. Voices from the North-African Immigrant Community in France. Immigration and Identity in Beur fiction. Bloomsbury Publishing Plc.

Hargreaves, Alec G. 1995. "La littérature issue de l'immigration maghrébine en France: une littérature 'mineure'?" in Bonn, Charles, Etudes littéraires maghrébines. Littérature des immigrations: un espace littéraire émergent. Paris, L'Harmattan.

Huston, Nancy; Sebbar, Leïla. 1986. Lettres parisiennes. Histoires d'exil. Paris, Bernard Barrault.

Hughes, Laurence. 2001. Écrits sous le voile. Romancières algériennes francophones, écriture et identité. Paris, Publisud.

Kessas, Ferrudja. 1990. Beur's story (écritures arabes). Paris, L’Harmattan Éditions.

Kettane, Nacer. 1986. Droit de réponse à la démocratie française. Paris, La Découverte.

LAIB, Nadjat. 2011. L'oralité comme source de renouvellement de l'écriture féminine dans Le Siècle des sauterelles, de Malika Mokeddem. Université Ferhat Abbas / Sétif. Argelia. Tesis doctoral dirigida por Said Khadraoui: $<$ https://bit.ly/3djIpOP $>$ [11/05/2021].

LARONDE, Michel. 1993. "Autour du roman beur. Immigration et Identité" in Hommes \& Migrations, 1166, 65-75: <https://bit.ly/2I9NYUt> [15/04/2021].

Ledoux-Beaugrand, Evelyne. 2005. "N'être rien: ni Françaises, ni Maghrébines. Stratégies de déplacement et de départenance dans la littérature des femmes beures" in Initiales/ Initials, 20, 47-69.

Lejeune, Philippe. 1975. Le pacte autobiographique. Paris, Seuil.

Mangada CAÑAs, Beatriz. 2014. "Analyse de la contribution de trois voix littéraires à la dimension féminine de la francophonie maghrébine" in Çédille. Revista de Estudios Franceses, 10, 207-220. 
MCILvanney, Siobhán. 2018. "The articulation of beur female identity in the works of Farida Belghoul, Ferrudja Kessas and Soraya Nini" in Gill Rye and Michael Worton, Women's writing in contemporary France. New writers, new literatures in the 1990s. Manchester University Press, 130-141:<DOI: 10.7765/9781526137999.00016> [18/05/2021].

Merniz, Nora. 2003 [2002]. Famille nombreuse. L'Act Mem (coll. La polygraphe).

Mokeddem, Malika. 2006. in AmnAy, Idir: "Malika Mokeddem écrivaine 'l'acte d'écriture est ma première liberté" in El Watan, culture, 12 septembre 2006: <https://n9.cl/yj8tu> $[12 / 05 / 2021]$.

Naudier, Delphine; Ravet, Hyacinthe. 2005. "Création artistique et littéraire" in Maruani Margaret, Femmes, genre et société. Paris, La découverte, 414-423.

NINI, Soraya. 1993. Ils disent que je suis une beurette. Paris, Fixot.

PanaïTe, Oana. 2012. Des littératures-mondes en français: Écritures singulières, poétiques transfrontalières dans la prose contemporaine. Rodopi. Amsterdam/New York.

Petit, Michèle. 2008. L'art de lire ou comment résister à l'adversité. Paris, Belin.

Petrescu, Maria. 2010. “Conflit et intégration dans Le Sourire de Brahim de Nacer Kettan et Kiffe Kiffe demain de Faïza Guène" in Les Cahiers du GRELCEF, 1. L'Entre-deux dans les littératures d'expression française, Mai, 111-128.

Redouane, Najib \& Yvette Benayoun-Szmidt. 2012. Qu'en est-il de la littérature "beur" au féminin? Paris, L'Harmattan.

Redounne, Najib; Benayoun-Szmidt, Yvette. 2014. Les Franco-Maghébines: autres voix / écritures autres. Paris, L'Harmattan (coll. Autour des textes maghrébins): <https://bit. ly/322UKD2> [12/08/2021].

REECK, Laura. 2012. "La littérature beur et ses suites. Une littérature qui a pris ses ailes" in Hommes \& migrations, 1295, 120-129: <http://hommesmigrations.revues.org/1077> [23/05/2021].

Ricceur, Paul. 1990 [1970]. Soi-même comme un autre. Paris, Le Seuil.

Rios Martinez, Jhon Fredy. 2015. Identité linguistique et culturelle dans le roman francomaghrébin. Tesis de doctorado dirigida por Ricard Ripoll Villanueva, Universitat Autònoma de Barcelona: <https://bit.ly/30OcH78> [22/04/2021].

Rosello, Mireille. 1996. Infiltrating Culture: Power and Identity in Contemporary Women's Writing. Manchester et New York, Manchester University Press.

Rosello, Mireille. 1993. "Georgette! de Farida Belghoul: Télévision et départenance" in L'Esprit Créateur, 33(2), Summer, 35-46. Published by Johns Hopkins University Press: $<$ https://doi.org/10.1353/esp.1993.0063> [25/04/2021].

Schmidt, Sophie. 2016. La quête identitaire des beurettes dans le roman beur. Hausarbeit (Hauptseminar): <https://bit.ly/2IehJnh> [12/03/2021].

Sebbar, Leïla. 1982. Shérazade, 17 ans brune, frisée, les yeux verts. Stock. 
Anales de Filología Francesa, n. ${ }^{\circ}$ 29, 2021

SOLEDAD DÍAZ ALARCÓN

Segarra, Marta. 1997. Leur pesant de poudre: romancières francophones du Maghreb. Paris, l'Harmattan.

Slimani, Leïla. 2018. Comment j'écris. Paris, Éditions de l'aube.

VIDEAU, André. 1988. "Le roman beur en question" in Hommes \& migrations, 1112, abrilmai, 7-11: <https://bit.ly/33JAyHh> [22/05/2021].

Wallet, William; Nehas, Abeljalil \& Mahjoub Sghiri. 1996. Les perspectives des jeunes issus de l'immigration maghrébine. Paris, L'Harmattan. 
